\title{
Synergistic Effects of Schwann- and Muscle-Derived Factors on Motoneuron Survival Involve GDNF and Cardiotrophin-1 (CT-1)
}

\author{
Vilma Arce, ${ }^{1 \star}$ Richard A. Pollock, ${ }^{* \star}$ Jean-Marc Philippe, ${ }^{1}$ Diane Pennica, ${ }^{2}$ Christopher E. Henderson, ${ }^{1}$ and \\ Odile deLapeyrière ${ }^{1}$ \\ 1/nstitut National de la Santé et de la Recherche Médicale (INSERM) U.382, Developmental Biology Institute of Marseille \\ (Centre National de la Recherche Scientifique-INSERM-Université de la Méditerranée), Campus de Luminy, 13288 \\ Marseille, France, and ${ }^{2}$ Department of Molecular Oncology, Genentech Incorporated, South San Francisco, California \\ 94080
}

The survival of central neurons depends on multiple neurotrophic factors produced by different cell types. We demonstrate that media conditioned by muscle and Schwann cell lines show strong synergistic effects on survival of purified embryonic day 14.5 rat motoneurons in culture. Different lines of evidence implicate glial cell line-derived neurotrophic factor (GDNF) and cardiotrophin-1 (CT-1) in this synergy. Their expression in the environment of the motoneuron is compartmentalized: gdnf transcripts are expressed principally in Schwann cell lines, whereas ct-1 mRNA is present in myotubes. Blocking antibodies to GDNF inhibit the trophic activity of Schwann cell lineconditioned media by $75 \%$, whereas CT-1 antibodies diminish the myotube-derived activity by $46 \%$. CT- 1 and GDNF act synergistically to enhance motoneuron survival in vitro. In vivo, individual motoneurons coexpress both GDNF and CT-1 receptor components. GDNF and CT-1, therefore, are major components of the trophic support provided by the Schwann and muscle cells, respectively. The possibility that they act together on individual motoneurons suggests that the motoneuron must integrate distinct signals from different cellular partners when deciding whether to die or to survive.

Key words: motoneuron survival; neurotrophic factors; synergy; GDNF; cardiotrophin-1; CNTF; Schwann cells; muscle cells; blocking antibodies; in situ hybridization
Motoneurons undergo a phase of natural developmental cell death that leads to loss of approximately half of the motoneurons initially generated. The surviving motoneurons have established contact with their target muscle and are assumed to have access to trophic factors essential for their survival (Hamburger, 1977; Oppenheim, 1989). Several studies have identified a variety of neurotrophic factors capable of supporting the survival of motoneurons (for review, see Henderson, 1996; Oppenheim, 1996). These include the cytokines ciliary neurotrophic factor (CNTF) and cardiotrophin-1 (CT-1) and the glial cell line-derived neurotrophic factor (GDNF), a member of the transforming growth factor- $\beta$ (TGF $\beta)$ superfamily.

CT- 1 belongs to the same IL-6 cytokine family as CNTF (Pennica et al., 1995). Among these cytokines, Leukemia Inhibitory Factor (LIF), CNTF, and CT-1 induce gp130 heterodimerization with a protein related to gp130, LIFR $\beta$. In addition, $\mathrm{CNTF}$ and CT-1 require a third receptor component (CNTFR $\alpha$

Received Oct. 20, 1997; revised Nov. 26, 1997; accepted Dec. 9, 1997.

This work was funded by Institut National de la Santé et de la Recherche Médicale (INSERM), Centre National de la Recherche Scientifique (CNRS), the Association Française contre les Myopathies (AFM), the Institut pour la Recherche sur la Moelle Epinière (IRME), and European Commission contract CT960433. R.A.P. was supported by the Wellcome Trust, and J.M.P. was supported by Association pour la Recherche sur le Cancer (ARC) and AFM. We thank S. Alonso fo help with the culture of muscle cells. We acknowledge the generous gifts of rat GDNF from A. Rosenthal and rat CNTF from D. A. Shelton. We are grateful to G. Bennett (Genentech) for preparing the affinity-purified CT-1 antibodies and to R O'Leary (Genentech) for helping with the mouse CT-1 purification. We thank members of INSERM U.382 for many helpful discussions.

*The first two authors made equal contributions to this work.

Correspondence should be addressed to O. deLapeyrière, INSERM U.382, IBDM, Campus de Luminy, Case 907, 13288 Marseille Cedex 09, France.

Dr. Pollock's present address: Department of Pharmacology, Centre Medical Universitaire, 1 Rue Michel Servet, 1211 Geneve 4, Switzerland.

Copyright (C) 1998 Society for Neuroscience $0270-6474 / 98 / 181440-09 \$ 05.00 / 0$ for CNTF but still unidentified for CT-1) that is anchored to the cell membrane via a glycosylphosphatidylinositol (GPI) linkage (Davis et al., 1991; Pennica et al., 1996). GDNF signals through a receptor complex formed between the transmembrane tyrosine kinase Ret and the GPI-linked ligand-binding subunit GDNFR $\alpha$ (for review, see Robertson and Mason, 1997).

The role of some factors in the survival of motoneurons in vivo has been supported recently by gene knockout studies. For example, inactivation of the cytokine receptor components, chtfr $\alpha$ and lifr $\beta$, leads to a $40 \%$ loss of motoneurons (DeChiara et al., 1995; Li et al., 1995), whereas the absence of their ligands CNTF and LIF exhibits no phenotype (Sendtner et al., 1996). The loss of GDNF, shown to be the most potent motoneuron survival factor yet identified (Henderson et al., 1994), results in a significant loss of motoneurons (20-30\%) (Moore et al., 1996; Sanchez et al., 1996). GDNF and an unidentified ligand for $\operatorname{CNTFR} \alpha$, therefore, are likely to be important factors in the survival of some motoneurons.

The cellular origin of these factors appears to differ. GDNF is strongly expressed by embryonic Schwann cells at the beginning of the motoneuron cell death period and later by some muscles (Henderson et al., 1994; Wright and Snider, 1996) and CNTF is expressed by Schwann cells only postnatally (Sendtner et al., 1992), whereas skeletal muscle is one of the major tissues to express CT-1 during development (Henderson et al., 1994; Pennica et al., 1996; Sheng et al., 1996), clearly implying that neurotrophic factors are not necessarily all synthesized by the target muscle.

The identification of different cellular sources for these trophic factors and the complexity of growth factor requirements of neurons in the CNS (Snider, 1994) led us to hypothesize that 
signaling pathways for different factors may interact at the level of a single motoneuron to select those motoneurons that have established contact not only with their target but also with other cellular partners such as Schwann cells, glial cells, or interneurons. In accordance with this, we show that muscle and Schwann cells, the main peripheral partners of motoneurons, secrete factors that can act synergistically to promote motoneuron survival. Blocking the activity of CT-1 or GDNF in muscle- or Schwann cell line-conditioned media, respectively, significantly reduces the survival-promoting activity of each medium. This leads us to propose that GDNF and CT-1, two physiologically relevant factors, act in concert to ensure the correct development of motoneurons within a complex environment.

\section{MATERIALS AND METHODS}

Motoneuron purification and culture. Ventral spinal cords of embryonic day 14.5 (E14.5) Sprague Dawley rat embryos (Janvier) were dissected and dissociated, and motoneurons were isolated as described previously (Henderson et al., 1995). Briefly, motoneurons were purified by a combination of metrizamide density-gradient centrifugation and immunopanning on dishes coated with the 192 antibody (Chandler et al., 1984), which recognizes the low-affinity nerve growth factor (NGF) receptor and is specific for motoneurons at this stage (Yan and Johnson, 1988). Purified motoneurons were seeded on polyornithine/laminin-coated dishes at a density of 2000 cells per $35 \mathrm{~mm}$ dish or 800 cells per $16 \mathrm{~mm}$ well. Culture medium (basal medium) was Neurobasal (Life Technologies) supplemented with the B27 supplement (Life Technologies), horse serum $(2 \% \mathrm{v} / \mathrm{v})$, L-glutamine $(0.5 \mathrm{mM})$, and 2-mercaptoethanol $(25 \mu \mathrm{M})$. L-Glutamate $(25 \mu \mathrm{M})$ was added to the medium during the first $4 \mathrm{~d}$ of culture and subsequently omitted. For long-term cultures, medium was changed every 4-5 d.

Motoneuron survival was quantified as described previously (Pennica et al., 1996) by counting the number of large phase-bright neurons with long axonal processes in a predetermined area of $1.5 \mathrm{~cm}^{2}$ in the center of duplicate dishes. The number of motoneurons that developed initially in the presence of $100 \mathrm{pg} / \mathrm{ml} \mathrm{GDNF}$ after $24 \mathrm{hr}$ in culture was taken as $100 \%$ survival. Two B27 batches and several Neurobasal batches were used in this study. Combinations of different batches gave slightly different absolute survival values in basal medium and allow motoneuron survival for varied time in culture. To allow for comparison of values from different experiments, survival values were corrected for the value in basal medium (taken as $0 \%$ ) and expressed relative to the initial $100 \%$ value.

Neurotrophic factors. Recombinant neurotrophic factors rat GDNF, rat $\mathrm{CNTF}$, and neurturin were generously provided by Genentech, Inc. Mouse LIF was purchased from Life Technologies. The recombinant mouse CT-1 used in this study was produced in Escherichia coli, whereas that used in our previous work was purified from 293 mammalian cells. The percentage of motoneurons kept alive with this new batch was lower than that reported in our previous experiments (Pennica et al., 1996).

Neurotrophic factors were prepared as stock solutions $(1-10 \mu \mathrm{g} / \mathrm{ml})$ in PBS supplemented with $0.5 \%$ bovine serum albumin (Sigma) and kept in aliquots at $-70^{\circ} \mathrm{C}$. Once thawed, aliquots were kept at $4^{\circ} \mathrm{C}$ and used within 1 week.

Conditioned media. The C2/C7 muscle cell line (Catala et al., 1995) was expanded as myoblasts in DMEM with $20 \%$ fetal calf serum until confluent and then differentiated into myotubes in complete Neurobasal medium (described above). The medium was changed for fresh complete Neurobasal medium and conditioned by myotubes over a period of $3 \mathrm{~d}$. The MSC80 cell line (Boutry et al., 1992), kindly provided by B. Zalc (INSERM U.134, Paris, France), was expanded in DMEM with $10 \%$ fetal calf serum until confluent. The medium was changed for fresh complete Neurobasal medium and conditioned by Schwann cells for $24 \mathrm{hr}$.

Antibody blocking experiments. Blocking antibodies to GDNF (monoclonal mouse anti-human GDNF-neutralizing antibody; R\&D Systems Europe Ltd.) were reconstituted according to the supplier's instructions. Rabbit antiserum to CT-1 was affinity-purified through a CT-1 resin column as described previously (Pennica et al., 1996). The appropriate quantities of conditioned media, recombinant neurotrophic factors, and blocking antibodies (final concentration $20 \mu \mathrm{g} / \mathrm{ml}$ ) for $0.4 \mathrm{ml}$ were incubated together in $16 \mathrm{~mm}$ polyornithine/laminin-coated culture wells in a total volume of $0.2 \mathrm{ml}$ of basal medium. After $1 \mathrm{hr}$ in the $\mathrm{CO}_{2}$ incubator at $37^{\circ} \mathrm{C}, 0.2 \mathrm{ml}$ of a suspension of motoneurons ( 4000 cells $/ \mathrm{ml}$ ) in basal medium was added. The contents of each well were aspirated once into a blue micropipette tip and then gently expelled to ensure uniform distribution of motoneurons. To evaluate motoneuron survival, wells were filled with warm L15 medium and the cover of the dish was replaced. The number of surviving motoneurons was counted across the diameter of the well in two perpendicular directions.

RT-PCR analysis. C2/C7 myoblasts and myotubes were taken as muscle cells, whereas TSC2 (Knight et al., 1993), kindly provided by J. Koenig (University of Bordeaux) and MSC80 were used as Schwann cells. Total RNA was isolated using the Trizol reagent (Life Technologies) and treated with RNase-free DNase I (Boehringer Mannheim). Reversetranscription reactions, PCR, and electrophoresis were performed using standard protocols as described previously for $c t-1$ (Pennica et al., 1996), gapdh, and gdnf (Henderson et al., 1994), except that the number of cycles was 30 for gapdh, 39 for $c t-1$, and 36 for gdnf.

Probes. A $1176 \mathrm{nt}$ full-length mouse cntfr $\alpha$ clone, including a $1169 \mathrm{nt}$ region with $95 \%$ identity to the published rat cntfr $\alpha$ sequence (nt 621230 in Genbank S54212) in pBluescript II (pBs) and an $800 \mathrm{nt}$ mouse lifr $\beta$ clone representing the middle third of the extracellular domain (nt $820-1620$ in Genbank D26177) in pBs were used to prepare transcripts labeled with digoxigenin-UTP (DIG-UTP). A 1610 nt rat $g d n f r \alpha$ clone with $>99 \%$ identity to the published rat $g d n f r \alpha$ sequence (nt 247-1856 in Genbank U59486) in pBs and a c-ret clone pmcret7 (Pachnis et al., 1993) (including nt 1444-2864 in Genbank X67812) in pBs were used to prepare transcripts labeled with fluorescein-UTP (Fluo-UTP).

Double in situ hybridization. In situ hybridizations were performed on $16-\mu \mathrm{m}$-thick frozen sections prepared from E14.5 rat embryos fixed with $4 \%$ paraformaldehyde in $0.12 \mathrm{~m}$ phosphate buffer, $\mathrm{pH} 7.4$, and cryopreserved in $15 \%$ sucrose and $0.12 \mathrm{M}$ phosphate buffer, $\mathrm{pH} 7.2$, before embedding in the same buffer plus $7.5 \%$ gelatin.

Labeled probes were transcribed using the Boehringer T3/T7 transcription kit. Transcripts were hydrolyzed to give an average probe length of $150 \mathrm{bp}$ and were used at a concentration of $500 \mathrm{ng} / \mathrm{ml}$. The double in situ hybridization protocol was adapted from those described by Myat et al. (1996) and by Jowett and Yan (1996), except that in this study the two color reaction products were analyzed separately to avoid complications arising from superimposition of the two signals. This was achieved by recording the Fast Red reaction results and then bleaching the sections before recording the second color reaction for which we used NBT/BCIP instead of using fluorescent ELF-TM. Briefly, as described by Myat et al. (1996), DIG- and Fluo-labeled probes were mixed in hybridization buffer and applied to sections. After hybridization at $70^{\circ} \mathrm{C}$ overnight, sections were washed twice in $50 \%$ Formamide, $1 \times$ SSC, $0.1 \%$ Tween-20 for $30 \mathrm{~min}$ at $65^{\circ} \mathrm{C}$, twice in MABT buffer for $30 \mathrm{~min}$ before blocking in buffer A (MABT, 2\% blocking reagent from Boehringer Mannheim, 20\% sheep serum) for $1 \mathrm{hr}$. Sections were then exposed to a 1:5000 dilution of anti-DIG-alkaline phosphatase (AP)-conjugate (Boehringer Mannheim) in buffer A overnight at room temperature. After washing for $30 \mathrm{~min}$ in MABT, the bound DIG-probe was visualized by an AP-catalyzed color reaction using Fast Red (Boehringer Mannheim) according to the manufacturer's instructions. The color reaction was stopped in water, the slides were mounted in $90 \%$ glycerol and $0.1 \mathrm{M}$ Tris, $\mathrm{pH} 8.2$, and the results were recorded as photomicrographs taken using DIC optics. The AP activity was then inactivated by incubating with $100 \mathrm{~mm}$ glycine and $0.1 \%$ Tween-20, $\mathrm{pH} 2.2$, for $30 \mathrm{~min}$, and the sections were post-fixed in 4\% PFA in PBS for $10 \mathrm{~min}$ at room temperature, washed in PBS, blocked again in buffer A for $1 \mathrm{hr}$, and incubated overnight with anti-Fluo-AP conjugate (Boehringer Mannheim). After washing as above, slides were incubated this time with NBT-BCIP (Boehringer Mannheim, Meylan, France) staining solution according to the manufacturer's instructions and the reaction stopped by washing in water. Fast Red precipitates were then removed by incubating the slides in increasing concentrations of ethanol, culminating in two final incubations in $100 \%$ ethanol for $10 \mathrm{~min}$ before cleaning with Histoclear and mounting with Eukitt (Poly Labo). Photomicrographs of the NBT/BCIP results were then taken for comparison with those showing the Fast Red results on the same sections. This sequential approach permits unequivocal identification of coexpression at the single cell level. Control experiments in which sections were hybridized with only one probe and nevertheless exposed to both antibodies sequentially were used to confirm both antibody specificity and successful alkaline phosphatase inactivation (data not shown). 

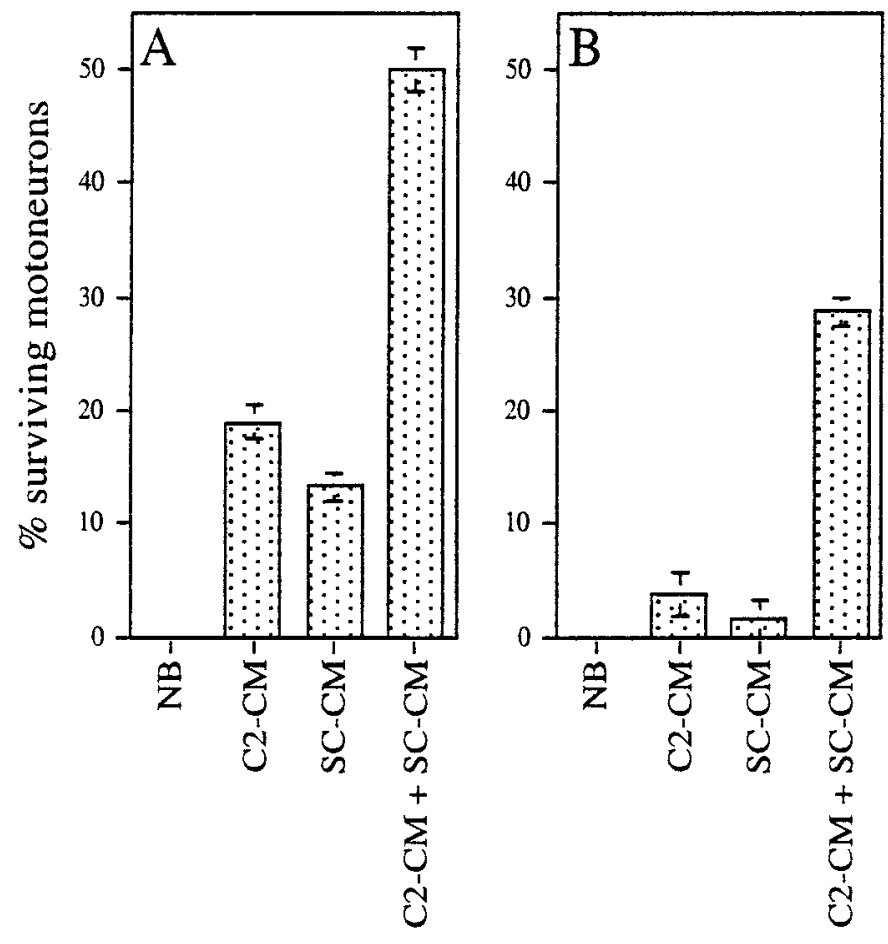

Figure 1. Synergy between Schwann cell- and myotube-conditioned media on motoneuron survival. C2 myotube-conditioned medium (C2-CM) and MSC80 Schwann cell-conditioned medium $(S C-C M)$ were tested alone or in combination after $6 \mathrm{~d}(A)$ and $10 \mathrm{~d}(B)$ of culture. Each medium was used at a concentration of $10 \%(\mathrm{v} / \mathrm{v})$ in neurobasal $(N B)$ medium. The number of motoneurons per field was determined and expressed relative to the number of motoneurons surviving in $100 \mathrm{pg} / \mathrm{ml}$ GDNF determined after $24 \mathrm{hr}$ of culture and taken as $100 \%$. Means \pm SEM for duplicate dishes are shown. Strong synergy is observed between $\mathrm{C} 2-\mathrm{CM}$ and SC-CM.

\section{RESULTS}

\section{Schwann cell- and myotube-conditioned media act in concert to promote motoneuron survival}

We first asked whether different tissues in close contact with motoneurons can act synergistically on the survival of purified motoneurons. We used cell lines to avoid contamination by other cell types, because it is not possible to obtain primary cultures of rodent myotubes that are completely free of fibroblasts and Schwann cells. Myotube-conditioned medium (C2$\mathrm{CM}$ ) was prepared using the mouse $\mathrm{C} 2 / \mathrm{C} 7$ muscle cell line, which can form neuromuscular junctions in vitro (Jo et al., 1995), and Schwann cell-conditioned medium (SC-CM) from the mouse MSC80 cell line, which can successfully form myelin when associated with axons in vivo (Boutry et al., 1992). Using the long-term culture system for E14.5 rat motoneurons that we developed previously (Pennica et al., 1996), we tested the ability of conditioned media, alone or in combination, to sustain motoneuron survival for different periods of time in culture. As shown previously (Yamamoto et al., 1997), both media when used at optimal concentrations $(10 \% \mathrm{v} / \mathrm{v})$ supported purified motoneurons in culture over $6 \mathrm{~d}$; a typical experiment is shown in Figure $1 A$. On average, SC-CM saved $11 \pm 3 \%$ (mean $\pm \mathrm{SEM}, n=2)$ of total motoneurons and C2-CM $20 \pm 1 \%$. However, individually their action was nearly undetectable in long-term cultures. After $10 \mathrm{~d}$, very few of the motoneurons initially present were saved by $\mathrm{C} 2-\mathrm{CM}$ or by SC-CM (Fig. $1 B$ ) (on average, $3.5 \pm 1 \%$ and $2 \pm 1 \%$,

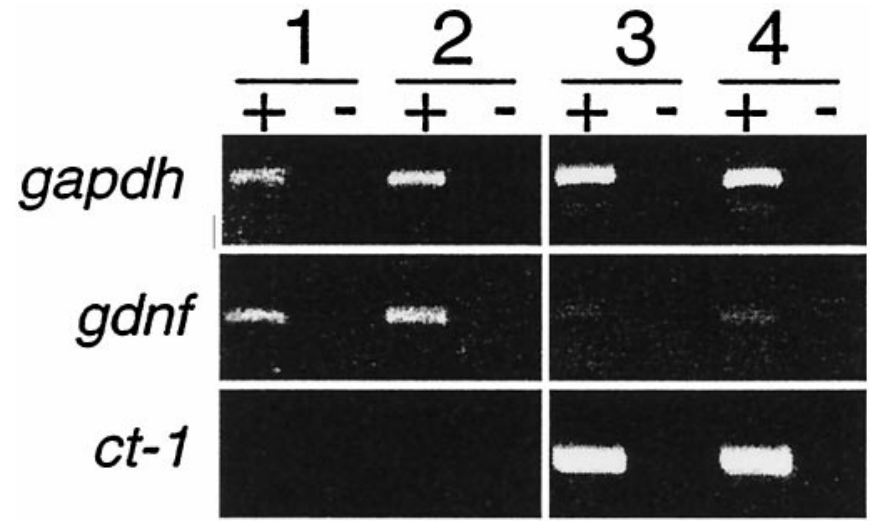

Figure 2. Expression of $g d n f$ and $c t-1$ mRNAs is compartmentalized in the environment of the motoneuron. RT-PCR analysis of RNA extracted from Schwann cell lines [TSC2 (lane 1) and MSC80 (lane 2)] and from muscle cells [C2/C7 myoblasts (lane 3) and $\mathrm{C} 2 / \mathrm{C} 7$ myotubes (lane 4)]. Signal for $c t-1$ was detected only in mRNA from muscle cells, whereas gdnf mRNA was more abundant in Schwann cells than in myoblasts or myotubes. gapdh was used as a positive control. PCR reactions were performed on the same RNA samples incubated with $(+)$ or without $(-)$ reverse transcriptase.

respectively). Strikingly, however, when applied in combination, SC-CM and C2-CM were found to act synergistically to promote motoneuron survival in both short-term and longterm cultures. Using $10 \%$ of each medium together on the same culture, the number of surviving motoneurons at $6 \mathrm{~d}$ was on average $52 \pm 2 \%$ and at $10 \mathrm{~d}$ was $25 \pm 4 \%$. These numbers greatly exceeded the sum of the motoneurons surviving in each medium alone, consistent with true synergy (Fig. 1). Thus, using conditions in which neither conditioned medium alone is sufficient to support motoneuron survival, Schwann cell- and C2 muscle cell-derived factors can act synergistically to keep a significant fraction of motoneurons alive on a long-term basis.

\section{Expression of gdnf and ct-1 in the environment of the motoneuron is compartmentalized}

The synergistic actions of Schwann cell- and muscle cell-derived media suggested that they must contain different neurotrophic factors. Among the trophic factors known to be active on motoneurons, we focused on two factors synthesized by Schwann cells or muscle cells: GDNF and CT-1 (Henderson et al., 1994; Oppenheim et al., 1995; Yan et al., 1995; Pennica et al., 1996). Because the cellular resolution of published in situ hybridization data for these neurotrophic factors is insufficient to identify the positive cell types, we used RT-PCR to determine which neurotrophic factors were potentially synthesized by Schwann and muscle cells.

We performed RT-PCR on RNA prepared from C2 myoblasts and myotubes or from MSC80 and TSC2 Schwann cells (Fig. 2). The results show that expression of $g d n f$ and $c t-1$ mRNAs is compartmentalized. Whereas the expression of $g d n f$ was much stronger in Schwann cells than in myoblasts or myotubes, ct-1 transcripts were detected only in muscle cells, myoblasts, and myotubes (Fig. 2). This is in accordance with the strong accumulation of $g d n f$ mRNA in peripheral nerve at the beginning of motoneuron cell death (Henderson et al., 1994; Wright and Snider, 1996) and is consistent with the pattern of $c t-1$ expression detected by in situ hybridization (Pennica et al., 1996). 


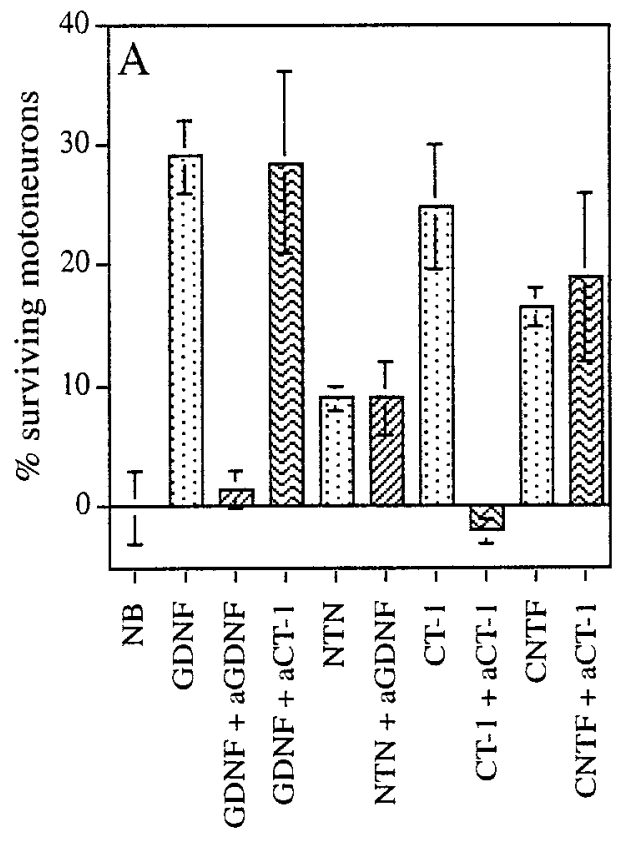

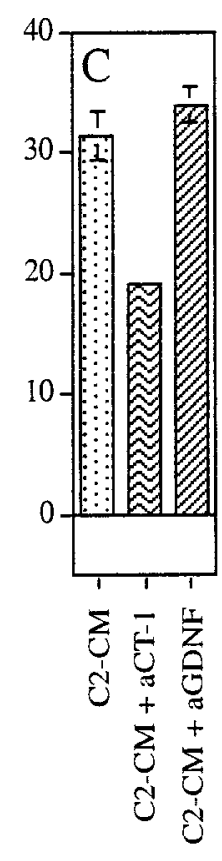

Figure 3. GDNF and CT-1 are major components of the trophic activity of Schwann cell- and myotube-conditioned medium, respectively. $A$, Blocking antibodies inhibit the activity of the relevant factor and show no toxic activity in the presence of irrelevant factors. $B$, Blocking antibodies to $G D N F$ strongly inhibit the trophic activity of SC-CM. $C$, Blocking antibodies to $C T-1$ diminish the activity of $C 2$ $C M$. The effects of antibody depletion were measured using purified motoneurons. Antibodies $(20 \mu \mathrm{g} / \mathrm{ml})$ were preincubated for $1 \mathrm{hr}$ at $37^{\circ} \mathrm{C}$ in the presence of the indicated factor or conditioned medium: GDNF (100 pg/ml), CT-1 (10 ng/ml), neurturin (NTN, $100 \mathrm{pg} / \mathrm{ml}), C N T F(10 \mathrm{ng} / \mathrm{ml})$. The number of motoneurons surviving after $3 \mathrm{~d}$ in culture is expressed as actual motoneuron counts per diameter of a $16 \mathrm{~mm}$ well; survival values in neurobasal medium $(N B)$ have been subtracted. Means \pm SEM in $A-C$ are from the same experiment but have been separated for clarity.

\section{GDNF and CT-1 contribute to the trophic support provided by Schwann and muscle cells, respectively}

To examine whether the trophic activity of conditioned media was attributable in part to the presence of CT-1 or GDNF, we performed antibody depletion experiments using blocking antibodies directed against either factor. Each antibody was capable of blocking the activity of the appropriate protein, but neither showed nonspecific toxicity for motoneurons grown in the presence of other factors, including members of the same family: neurturin for GDNF and CNTF for CT-1 (Fig. $3 A$ ). The number of motoneurons supported by rat GDNF $(100 \mathrm{pg} / \mathrm{ml})$ was reduced to basal levels by anti-human GDNF $(20 \mu \mathrm{g} / \mathrm{ml})$ but was not significantly affected by anti-CT1. Conversely, the trophic activity of mouse CT-1 (10 ng/ml) was inhibited by affinity-purified blocking antibodies to mouse CT-1 $(20 \mu \mathrm{g} / \mathrm{ml})$ but was not significantly affected by anti-GDNF (Fig. $3 A$, data not shown).

C2-CM and SC-CM $(10 \% \mathrm{v} / \mathrm{v})$ were incubated for $1 \mathrm{hr}$ at $37^{\circ} \mathrm{C}$ with blocking antibodies directed against each factor before seeding motoneurons. Strikingly, whereas anti-GDNF antibodies reduced by approximately threefold the number of motoneurons supported by SC-CM (Fig. 3B), they had no effect on C2-CM activity (Fig. 3C). Conversely, preincubation with anti-CT-1 antibodies strongly reduced the survival of motoneurons in the presence of $\mathrm{C} 2-\mathrm{CM}$ but did not alter the number of motoneurons saved by SC-CM (Fig. 3B,C). In three independent experiments, GDNF antibodies inhibited the trophic activity of SC-CM by $75 \pm 4 \%$ and $\mathrm{CT}-1$ antibodies reduced the trophic activity of $\mathrm{C} 2-\mathrm{CM}$ by $46 \pm 4 \%$. Thus, these results implicate GDNF as the major component of the trophic activity of SC-CM, and they implicate CT-1 as being responsible for almost half the C2-CM trophic activity for motoneurons. Furthermore, they confirm that muscle and Schwann cells provide different neurotrophic factors to maintain motoneuron survival during naturally occurring cell death.

\section{Synergy between GDNF and CT-1}

We next asked whether combinations of purified GDNF and CT- 1 could mimic the effects of SC-CM and C2-CM and thus act synergistically to promote motoneuron survival. In optimal conditions, GDNF and CT-1 alone allow the long-term survival of $25 \%$ and $40 \%$ of motoneurons initially seeded, respectively (Pennica et al., 1996). These figures are higher than those obtained above with SC-CM (2\%) and C2-CM (3.5\%), probably because the concentrations of factors in conditioned media were lower than those used in these experiments. Therefore, to distinguish better between additive and synergistic effects, we tested combinations of GDNF and CT-1 in experimental conditions that were suboptimal for single factors. Either the factors were added at lower concentrations or motoneurons were counted when the survival value with either factor alone had fallen below $20 \%$ (this time varied from one set of experiments to another; see Materials and Methods).

In these conditions, we established dose-response curves for CT-1 in the presence or absence of a fixed concentration of GDNF (100 pg/ml). In two independent experiments, after $14 \mathrm{~d}$ in culture, survival values for each factor were calculated by subtracting the number of motoneurons surviving in basal medium (absolute value). The fraction of motoneurons kept alive in the presence of $100 \mathrm{pg} / \mathrm{ml}$ GDNF was $2 \pm 2 \%$ (mean \pm SEM, $n=$ 2 ), and only $1 \pm 1 \%$ were saved by CT-1 (Fig. $4 A$ ). Combinations of both factors promoted the survival of up to $31 \pm 2 \%$ of motoneurons (Fig. 4A). Furthermore, the morphological development of surviving motoneurons was more pronounced in the presence of both factors (Fig. 4B1); compared with motoneurons cultured with either factor alone, those in the presence of GDNF plus CT-1 had twofold more primary neurites greater than two cell diameters in length (data not shown). These results demonstrate a strong synergy between GDNF and CT-1 on both survival and development of a fraction of motoneurons.

\section{GDNF acts synergistically with cytokines of the IL-6 family that use $\alpha$-subunits}

Because CT- 1 belongs to the IL- 6 cytokine family, we assessed whether GDNF could synergize with other members of this family. We established dose-response curves for the trophic activity of CNTF (Fig. 5A) or LIF (data not shown) in the 
A
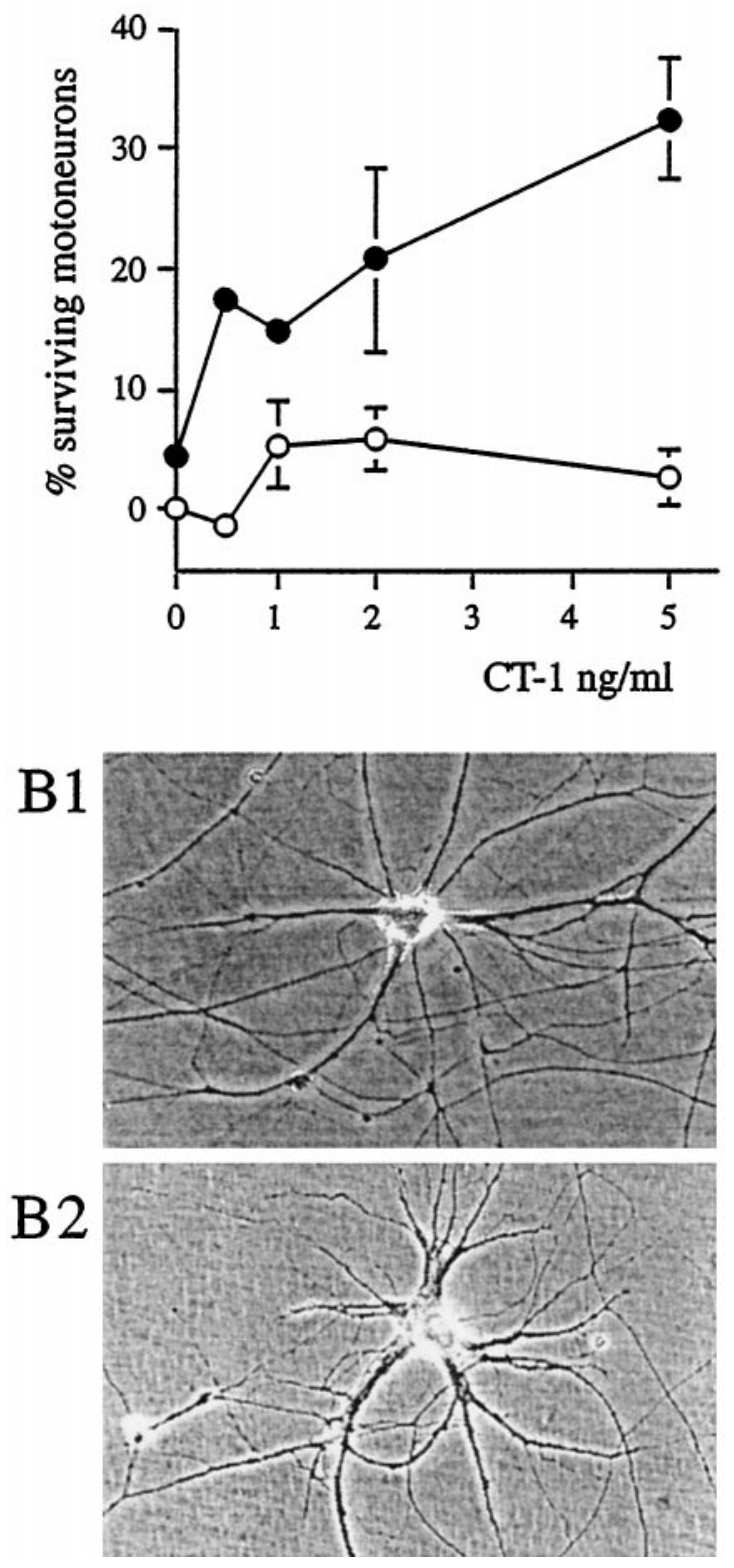

Figure 4. GDNF and CT-1 act synergistically to promote long-term survival of motoneurons. $A$, Increasing concentrations of CT-1 were tested for their long-term motoneuron survival activity in the presence $(\bullet)$ or absence $(\bigcirc)$ of a fixed concentration of $100 \mathrm{pg} / \mathrm{ml}$ GDNF. The number of motoneurons per field was determined after $14 \mathrm{~d}$ in culture and is expressed relative to the number of motoneurons surviving in 100 $\mathrm{pg} / \mathrm{ml}$ GDNF determined after $24 \mathrm{hr}$ of culture and taken as $100 \%$. Means \pm SEM for duplicate dishes, after correction for survival in basal medium (taken as $0 \%$ ), are shown. $B$, Phase-contrast micrographs of motoneurons maintained for $14 \mathrm{~d}$ in culture in the presence of $100 \mathrm{pg} / \mathrm{ml}$ GDNF supplemented with $5 \mathrm{ng} / \mathrm{ml} \mathrm{CT1} \mathrm{(B1)} \mathrm{or} 500 \mathrm{pg} / \mathrm{ml} \mathrm{CNTF} \mathrm{(B2).}$ Note the large multipolar cell body morphology.

presence or absence of a constant dose of GDNF (100 pg/ml). After $10 \mathrm{~d}$ in culture, survival values were calculated by subtracting the number of motoneurons surviving in basal medium. A typical experiment is shown in Figure $5 A$. In these conditions, on average $3 \pm 2 \%$ (mean $\pm \mathrm{SEM}, n=3$ ) were supported by CNTF $(500 \mathrm{pg} / \mathrm{ml})$ alone, $18 \pm 7 \%$ by GDNF $(100 \mathrm{pg} / \mathrm{ml})$ alone, and
$54 \pm 8 \%$ by a combination of both. This latter figure greatly exceeded the sum of the fraction of motoneurons surviving in either factor alone. These results together with the observation that, as with GDNF and CT-1, cells appeared healthier in the presence of both factors (Fig. 4B2) than with one factor alone (data not shown), demonstrate that GDNF and CNTF can act synergistically to promote motoneuron survival and development.

In contrast, in three independent experiments, whereas LIF was active on motoneurons in short-term cultures (Henderson et al., 1994), no synergy was observed between GDNF and LIF regardless of the length of time the motoneurons were kept in culture (Fig. 5B). This observation supports our previous conclusion (Pennica et al., 1996) that CT-1 and LIF do not use the same receptor components on motoneurons.

To investigate whether CT-1, LIF, and CNTF, all members of the IL- 6 cytokine family, can act in synergy, motoneurons were grown with each factor alone and with combinations of these factors. Survival activity for each cytokine alone can be detected at $3 \mathrm{~d}$ in culture (data not shown). However, at $6 \mathrm{~d}$, whatever the combination of factors, the survival values were no different from that of either factor alone, whereas in the same experiment motoneurons were able to respond to the synergistic actions of GDNF with CT-1 or CNTF (Fig. $5 B$ ).

\section{Individual spinal motoneurons coexpress GDNF receptor and CNTF receptor in vivo}

Taken together, our results suggest that at least two factors can act on a single neuron. This cooperative effect requires the expression of receptors for both factors in the same cell. However, such coexpression might be a secondary effect of cell culture. To determine whether, just before programmed cell death, individual motoneurons are potentially capable of responding to both GDNF and CT-1 in vivo, we developed a novel technique for double in situ hybridization (see Materials and Methods).

Each factor under investigation signals through a multicomponent receptor. GDNF uses a complex formed between the transmembrane tyrosine kinase RET and the GPI-linked ligand binding subunit GDNFR $\alpha$, both of which are known to be expressed by motoneurons (Pachnis et al., 1993; Treanor et al., 1996). CT-1 and CNTF signaling in motoneurons requires the transmembrane subunits LIFR $\beta$ and gp130, in addition to $\operatorname{CNTFR} \alpha$, a GPI-linked $\alpha$ subunit for CNTF (Davis et al., 1991), and an as yet unidentified equivalent for CT-1 (Pennica et al., 1996). If individual motoneurons respond during embryonic development to GDNF and CT-1, they should express ret, gdnfr $\alpha$, gp130, and lifr $\beta$. If they are receptive to GDNF and a CNTF-like factor, the motoneurons should also express cntfr $\alpha$. To ascertain whether a single motoneuron can express at least one component of both receptor complexes, we studied coexpression on spinal cord sections.

Because for lifr $\beta$ only a mouse probe was available, we performed double in situ hybridization of lifr $\beta$ and ret on mouse spinal cords and double in situ hybridization of cntfr $\alpha$ and gdnfr $\alpha$ on rat spinal cords. At brachial levels of E12.5 mouse spinal cord, most motoneurons expressed both lifr $\beta$, which was revealed using Fast Red (Fig. 6A,C) and ret, which was revealed using NBT/ BCIP (Fig. $6 B, D$ ). Similar results were observed for expression of cntfr $\alpha$ (Fig. $6 E, G$ ) and $g d n f r \alpha$ (Fig. $6 F, H$ ) at the brachial level of E14.5 rat spinal cord. At higher magnification, coexpression was observed at the single cell level (Fig. $6 C, D, G, H$ ). Thus, a majority of motoneurons express both GDNF and cytokine receptors as programmed cell death is about to begin. 

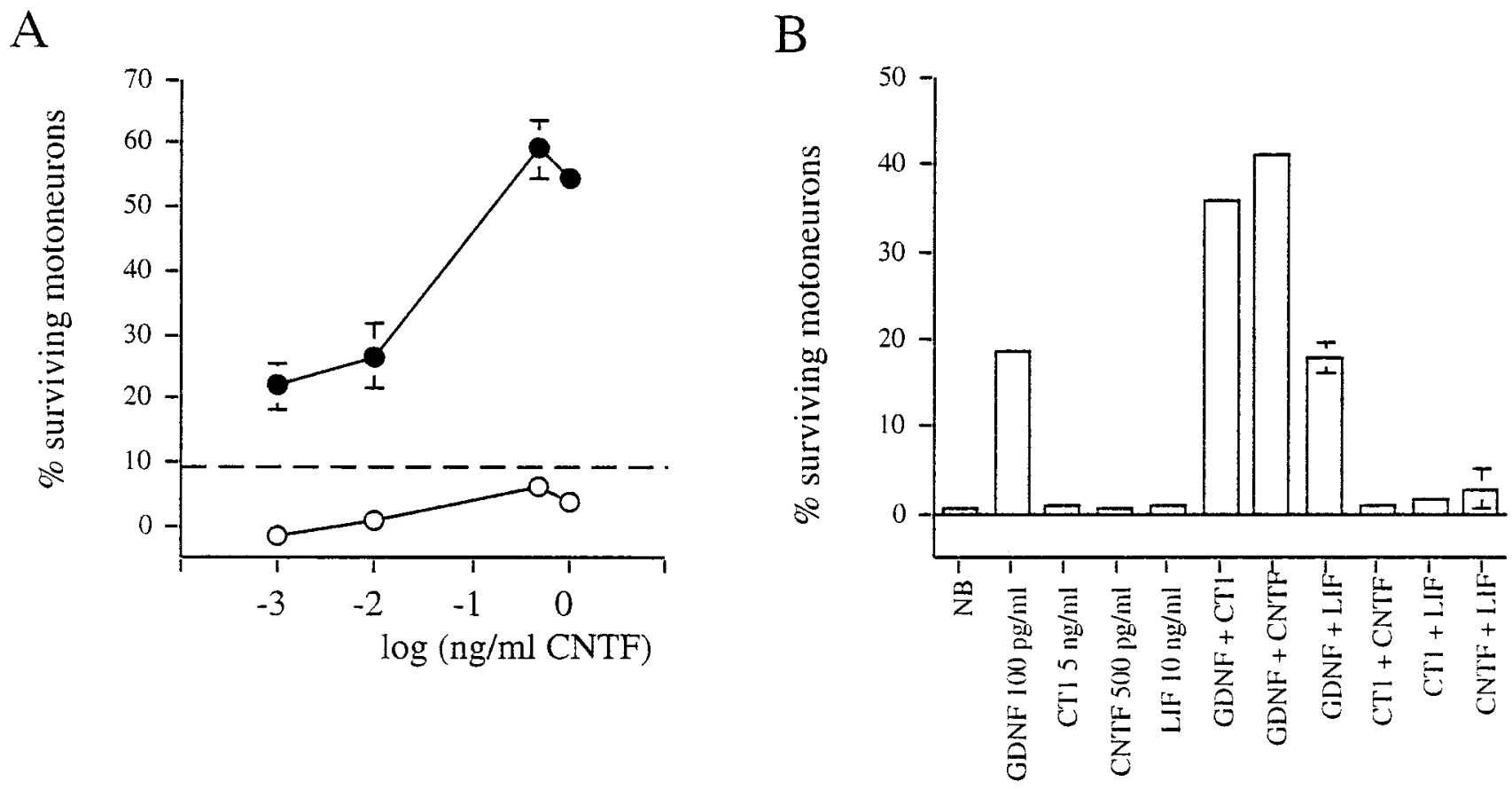

Figure 5. GDNF acts synergistically with two cytokines of the IL-6 family that use $\alpha$-subunits. Increasing concentrations of CNTF $(A)$ were added to motoneurons in the presence $(\bullet)$ or absence $(\bigcirc)$ of a fixed concentration of GDNF $(100 \mathrm{pg} / \mathrm{ml})$. The dashed line indicates the value obtained using GDNF alone. $B$, Comparison of motoneuron survival in the presence of cytokines alone and with combinations of these cytokines taken $2 \times 2$ as indicated. Survival values were determined after $10 \mathrm{~d}(A)$ or $6 \mathrm{~d}(B)$ in culture and are expressed as described in the legend to Figure 4 . All cytokines (CNTF, CT-1, and LIF) showed significant trophic activity at shorter survival times (not shown).

Of interest, the relative levels of intensity varied from one group of neurons to the other. For instance, as indicated in Figure 6, $C$ and $D$, some mouse motoneurons in the lateral part of the spinal cord showed a strong signal for ret and a weaker signal for lifr $\beta$. Similarly, a group of rat lateral motoneurons exhibited stronger staining for cntfr $\alpha$ (Fig. 6G) than for gdnfr $\alpha$ (Fig. $6 H$ ).

\section{DISCUSSION}

We have shown in the present study that two cell types in close contact with motoneurons, Schwann cells and muscle cells, synthesize molecules that have synergistic trophic effects on cultured motoneurons. We present evidence that major actors in this synergistic activity are GDNF and CT-1. These two factors are able to act in concert to promote significantly better motoneuron survival than either factor alone, and their expression in the environment of the motoneuron is compartmentalized: $g d n f$ is expressed mainly by Schwann cells, and $c t-1$ is expressed mainly by myotubes. In addition, blocking antibodies to GDNF inhibit $75 \%$ of the motoneuron trophic activity secreted by Schwann cell lines in culture, whereas blocking antibodies to $\mathrm{CT}-1$ reduce the trophic activity of myotube-conditioned medium by $46 \%$.

Synergistic effects of Schwann cells and muscle may reflect the complex cellular environment of central neurons (Snider, 1994). Thus, one might expect synergy between neurotrophic factors synthesized not only by peripheral but also by central (Yin et al., 1994) partners of the motoneuron. Such synergy has been demonstrated in vitro for the association of spinal cord cells and muscle (Dohrmann et al., 1987). Our hypothesis that motoneurons simultaneously need factors synthesized by different sources is difficult to test in vivo because it is difficult to establish the origin of a given factor. However, by extrapolating our in vitro results to the physiological situation in vivo, one would predict that deletion of either muscle or Schwann cells would lead to motoneuron loss. Indeed, in skeletal muscle-deficient transgenic mice carrying a cytotoxic gene controlled by a muscle-specific promoter, up to $90 \%$ of those motoneurons that normally would have survived are lost (Oppenheim et al., 1997). Furthermore, homozygous erbB3 mutant embryos, which lack Schwann cells, lose $79 \%$ of their motoneurons (Riethmacher et al., 1997).

Several arguments are in favor of GDNF as a physiological survival factor for some spinal motoneurons. First, it is a potent trophic factor for motoneurons in vitro, allowing the long-term survival of $\sim 25 \%$ of motoneurons initially seeded (Henderson et al., 1994). In ovo and in vivo, it rescues developing motoneurons from natural programmed cell death and prevents loss of neonatal motoneurons induced by axotomy (Henderson et al., 1994; Oppenheim et al., 1995; Yan et al., 1995). Furthermore, mutations in the gdnf gene are associated with loss of 20-30\% motoneurons (Moore et al., 1996; Sanchez et al., 1996). During embryonic development, in the environment of motoneurons, $g d n f$ is predominantly expressed in Schwann cells and later in some muscles (Henderson et al., 1994; Wright and Snider, 1996). Analysis of knockout mice cannot reveal the source of GDNF necessary for motoneuron survival. Here we have shown that incubation with GDNF blocking antibodies depletes $75 \%$ of the trophic activity of Schwann cell lines but has no significant effect on trophic activity of muscle cell lines, strongly suggesting that Schwann cells are the main source of GDNF for motoneurons.

CT-1 is also a potent trophic factor for motoneurons in vitro, and its pattern of expression is consistent with a physiological role in vivo. Indeed, levels of CT-1 mRNA are high in limb bud at the beginning of cell death and are greatly reduced at birth (Pennica et al., 1996). However, no knockout data are available to confirm 

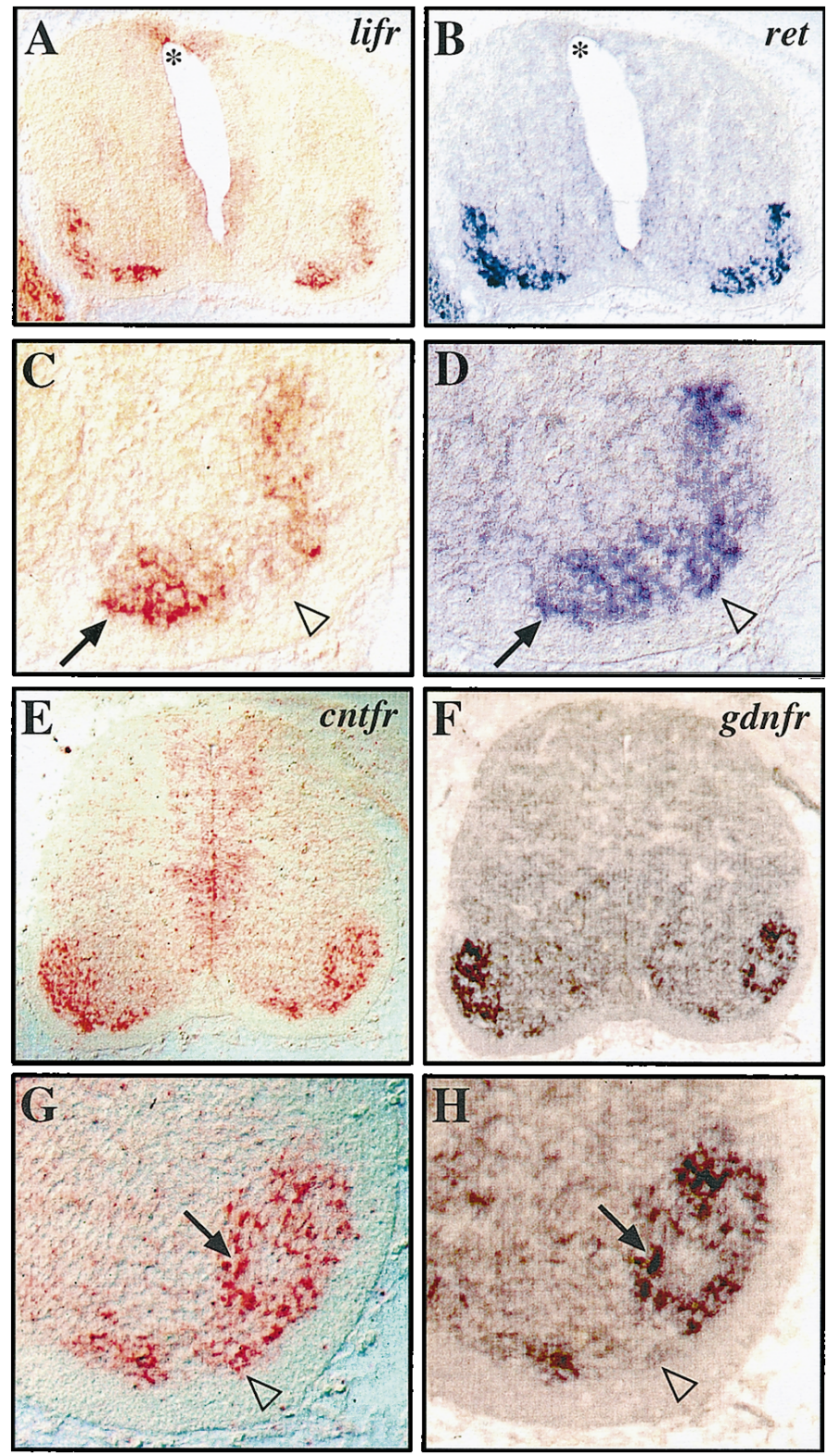

Figure 6. Double-labeling in situ hybridization detects expression of components of two different receptors in individual motoneurons. Single sections of E12.5 $(A-D)$ mouse and E14.5 $(E-H)$ rat brachial spinal cords were hybridized with two probes: DIG-labeled lifr $\beta$ and Fluo-labeled ret $(A-D)$ or DIG-labeled $c n t f r \alpha$ and Fluo-labeled $g d n f r \alpha(E-H)$. Anti-DIG antibodies were applied first and stained using Fast Red to reveal cells expressing lifr $\beta(A, C)$ and $c n t f r \alpha(E, G)$. Anti-Fluo antibodies were then applied and detected using NBT/BCIP to reveal cells expressing ret $(B, D)$ and $g d n f r \alpha(F, H)$ after removal of the first red reaction product. Most motoneurons express components of two receptor complexes (examples indicated by arrows). Compare enlargements of one mouse ventral horn in $C$ (lifr $\beta$ ) and $D$ (ret) and enlargements of one rat ventral horn in $G$ (cntfr $\alpha$ ) and $H$ ( gdnfr $\alpha$ ). Arrowheads indicate motoneurons that show a strong signal for ret $(D)$ and very low signal for $\operatorname{lifr} \beta(C)$ or that are positive for $\operatorname{cntfr} \alpha(G)$ and nearly negative for $g d n f r \alpha(H)$. Loss of lifr $\beta$ signal from roof plate (asterisk in $A$ and $B$ ) demonstrates lack of interference between color reactions.

the physiological relevance of CT-1 in vivo. We used antibody depletion to remove factors from conditioned medium, thus avoiding the possibility of a compensatory reaction by the cells in question. A $46 \%$ depletion of the $\mathrm{C} 2$ muscle trophic activity was observed after incubation with a blocking antibody to CT-1, showing not only the likely importance of CT-1 for motoneuron survival but also that it may indeed be one of the key musclederived factors.

We have shown that GDNF synthesized by Schwann cells and CT-1 secreted by muscle cells act synergistically to promote motoneuron survival. Synergistic effects of neurotrophic factors on motoneuron cultures have been reported previously (Zurn et al., 1996; Wong et al., 1997). However, this is the first time that a synergistic effect has been observed between factors present in the environment of motoneurons during naturally occurring cell death. Furthermore, the use of low-density cultures of purified motoneurons proves that both factors act directly on motoneurons and strongly suggests that synergy results from interactions at the level of single neurons. Exposure to a combination of several factors may induce synergy at the level of intracellular signaling pathways. In line with this consideration is the observation that GDNF and CT-1 may signal through different pathways: cytokines use the Jak-Tyk family of tyrosine kinases and the STATs (signal transducer and activator of transcription) as signaling substrates (for review, see Ip and Yancopoulos, 1996), whereas GDNF signaling involves the MAP kinase pathway (Trupp et al., 1996). Synergy at the signaling level was observed with $\mathrm{CNTF}$ and FGF, resulting in an increased and prolonged activation of the ERKs (Ip et al., 1994). Taken together, these data indicate that the distinct signaling pathways, activated on one hand by GDNF and on the other hand by CT-1 or CNTF or an as yet unknown CNTF relative that is present during naturally occurring cell death, can cooperate to promote the survival of motoneurons.

Does synergy between GDNF and CT-1 occur during motoneuron development in vivo? This is difficult to test directly as discussed above. However, we show here that elements of both receptor complexes are coexpressed by individual motoneurons. Although $C n t f r \alpha$, lifr $\beta, g d n f r \alpha$, and ret expression in motoneurons was described previously (Ip et al., 1993; Pachnis et al., 1993; MacLennan et al., 1996; Treanor et al., 1996), our results using double in situ for lifr $\beta$ and ret and for cntfr $\alpha$ and gdnfr $\alpha$ provide the first clear evidence that certain individual motoneurons are potentially capable of responding to both GDNF and CT-1 in vivo. We could not test for presence of the putative CT-1 $\alpha$-receptor, but our data strongly suggest that a combination of GDNF and CT-1 should provide an interesting pharmacological tool (Henderson, 1995) that may have important implications for clinical neuroscience. Indeed, in vivo synergy between CNTF and BDNF (Mitsumoto et al., 1994) or CNTF and NT3 (Haase et al., 1997) has been observed previously in the treatment of mouse models of degenerative motoneuron diseases.

GDNF and CT-1 are essential components of the neurotrophic activity of Schwann and muscle cell-conditioned media, respectively, as demonstrated by our antibody depletion experiments. However in neither case did we obtain complete inhibition. Thus, it is clear that GDNF is not the only Schwann cell-derived factor, as is also demonstrated by the fact that in mice lacking Schwann cells (Riethmacher et al., 1997) the loss of motoneurons is much greater than in GDNF knockout mice (Moore et al., 1996; Sanchez et al., 1996). Similar arguments can be applied to musclederived factors. Although muscle is absolutely required for survival of $90 \%$ of developing motoneurons (Oppenheim et al., 1997), CT-1 antibodies do not abolish all of the activity of muscle-conditioned medium. In agreement with this, two other factors, FGF-5 and HGF/SF, have been demonstrated to be responsible for part of the trophic activity of muscle cells (Hughes 


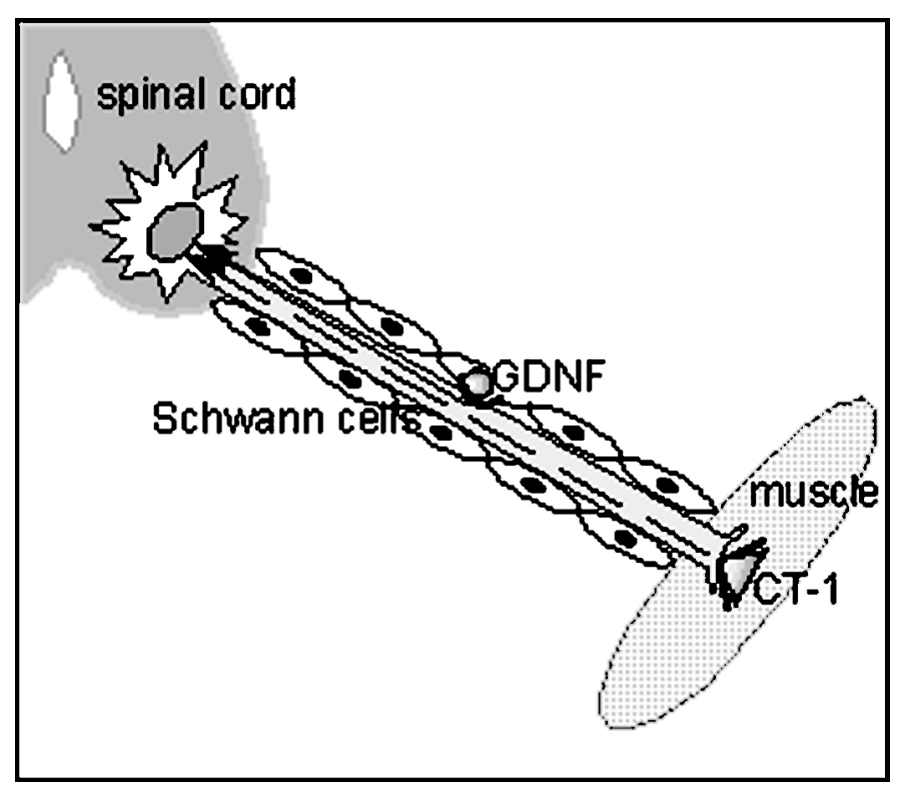

Figure 7. Diagram showing compartmentalized expression of GDNF and $\mathrm{CT} 1$ and their potential synergy. Two signaling pathways are activated: one by $C T-1$ (dashed line) produced by the muscle and the other by GDNF (solid line) coming from the Schwann cells. Successful activation of both pathways allows the long-term survival of motoneurons.

et al., 1993; Yamamoto et al., 1997). Other factors contributing to Schwann cell- and/or muscle-derived support for motoneurons may be relatives of CNTF that signal through the CNTF receptor. The proposed existence of such a "CNTF-2" molecule (DeChiara et al., 1995) may account for the strong synergy observed between GDNF and CNTF, which is not expressed during the period of motoneuron cell death.

Not all motoneurons respond to a combination of GDNF and CT-1, reflecting the likely complexity of motoneuron populations and raising the possibility of the existence of subpopulations. Our in situ hybridization data point to the existence of pools of motoneurons that express different levels of the receptor components we have studied (Fig. 6). The possible existence of subpopulations of motoneurons requiring different trophic factors implies that other combinations of factors might save other motoneurons. It is also possible that our Schwann- and muscle-cell lines may not reflect completely the diversity of Schwann and muscle populations in vivo in terms of neurotrophic factor production.

Our results provide evidence, and a potential rationale, for the existence of synergistic interactions between physiologically relevant neurotrophic factor signaling pathways in individual motoneurons. We suggest that the motoneuron (and other central neurons) can integrate distinct signals from several cellular partners when deciding whether to die or survive (Fig. 7). The existence of synergistic effects between Schwann- and musclederived factors would favor the survival of those motoneurons that have both made appropriate central connections and been surrounded by the cells that will constitute the myelinated peripheral nerve.

\section{REFERENCES}

Boutry JM, Hauw JJ, Gansmuller A, Di BN, Pouchelet M, Baron-Van Evercooren A (1992) Establishment and characterization of a mouse Schwann cell line which produces myelin in vivo. J Neurosci Res 32:15-26.

Catala F, Wanner R, Barton P, Cohen A, Wright W, Buckingham M
(1995) A skeletal muscle-specific enhancer regulated by factors binding to $\mathrm{E}$ and $\mathrm{CArG}$ boxes is present in the promoter of the mouse myosin light-chain 1A gene. Mol Cell Biol 15:4585-4596.

Chandler CE, Parsons LM, Hosang M, Shooter EM (1984) A monoclonal antibody modulates the interaction of nerve growth factor with PC12 cells. J Biol Chem 259:6882-6889.

Davis S, Aldrich TH, Valenzuela DM, Wong VV, Furth ME, Squinto SP, Yancopoulos GD (1991) The receptor for ciliary neurotrophic factor. Science 253:59-63.

DeChiara TM, Vejsada R, Poueymirou WT, Acheson A, Suri C, Conover JC, Friedman B, McClain J, Pan L, Stahl N, Ip NY, Kato A, Yancopoulos GD (1995) Mice lacking the CNTF receptor, unlike mice lacking CNTF, exhibit profound motor neuron deficits at birth. Cell 83:313-322.

Dohrmann U, Edgar D, Thoenen H (1987) Distinct neurotrophic factors from skeletal muscle and the central nervous system interact synergistically to support the survival of cultured embryonic spinal motor neurons [published erratum appears in Dev Biol 1988 126:215]. Dev Biol 124:145-152.

Haase G, Kennel P, Pettmann B, Vigne E, Akli S, Revah F, Schmalbruch H, Kahn A (1997) Gene therapy of murine motor neuron disease using adenoviral vectors for neurotrophic factors. Nat Med 3:429-436.

Hamburger V (1977) The developmental history of the motor neuron. Neurosci Res Progr Bull 15S:1-37.

Henderson CE (1995) Neurotrophic factors as therapeutic agents in amyotrophic lateral sclerosis: potential and pitfalls. Adv Neurol 68:235-240.

Henderson CE (1996) Role of neurotrophic factors in neuronal development. Curr Opin Neurobiol 6:64-70.

Henderson CE, Phillips HS, Pollock RA, Davies AM, Lemeulle C, Armanini M, Simpson LC, Moffet B, Vandlen RA, Koliatsos VE, Rosenthal A (1994) GDNF: a potent survival factor for motoneurons present in peripheral nerve and muscle. Science 266:1062-1064.

Henderson CE, Bloch-Gallego E, Camu W (1995) Purified embryonic motoneurons. In: Nerve cell culture: a practical approach (Cohen J, Wilkin G, eds), pp 69-81. London: Oxford UP.

Hughes RA, Sendtner M, Goldfarb M, Lindholm D, Thoenen H (1993) Evidence that fibroblast growth factor 5 is a major muscle-derived survival factor for cultured spinal motoneurons. Neuron 10:369-377.

Ip NY, Yancopoulos GD (1996) The neurotrophins and CNTF: two families of collaborative neurotrophic factors. Annu Rev Neurosci 19:491-515.

Ip NY, McClain J, Barrezueta NX, Aldrich TH, Pan L, Li Y, Wiegand SJ, Friedman B, Davis S, Yancopoulos GD (1993) The alpha component of the CNTF receptor is required for signaling and defines potential CNTF targets in the adult and during development. Neuron 10:89-102.

Ip NY, Boulton TG, Li Y, Verdi JM, Birren SJ, Anderson DJ, Yancopoulos GD (1994) CNTF, FGF, and NGF collaborate to drive the terminal differentiation of MAH cells into postmitotic neurons. Neuron 13:443-455.

Jo SA, Zhu X, Marchionni MA, Burden SJ (1995) Neuregulins are concentrated at nerve-muscle synapses and activate ACh-receptor gene expression. Nature 373:158-161.

Jowett T, Yan YL (1996) Double fluorescent in situ hybridization to zebrafish embryos. Trends Genet 12:387-389.

Knight RM, Fossom LH, Neuberger TJ, Attema BL, Tennekoon G, Bharucha V, DeVries GH (1993) Increased P0 glycoprotein gene expression in primary and transfected rat Schwann cells after treatment with axolemma-enriched fraction. J Neurosci Res 35:38-45.

Li M, Sendtner M, Smith A (1995) Essential function of LIF receptor in motor neurons. Nature 378:724-727.

MacLennan AJ, Vinson EN, Marks L, McLaurin DL, Pfeifer M, Lee N (1996) Immunohistochemical localization of ciliary neurotrophic factor receptor alpha expression in the rat nervous system. J Neurosci 16:621-630.

Mitsumoto H, Ikeda K, Klinkosz B, Cedarbaum JM, Wong V, Lindsay RM (1994) Arrest of motor neuron disease in wobbler mice cotreated with CNTF and BDNF. Science 265:1107-1110.

Moore MW, Klein RD, Farinas I, Sauer H, Armanini M, Phillips H, Reichardt LF, Ryan AM, Carver-Moore K, Rosenthal A (1996) Renal and neuronal abnormalities in mice lacking GDNF. Nature 382:76-79.

Myat A, Henrique D, Ish-Horowicz D, Lewis J (1996) A chick homologue of Serrate and its relationship with Notch and Delta homologues during central neurogenesis. Dev Biol 174:233-247. 
Oppenheim RW (1989) The neurotrophic theory and naturally occurring motoneuron death. Trends Neurosci 12:252-255.

Oppenheim RW (1996) Neurotrophic survival molecules for motoneurons: an embarrassment of riches. Neuron 17:195-197.

Oppenheim RW, Houenou LJ, Johnson JE, Lin LF, Li L, Lo AC, Newsome AL, Prevette DM, Wang S (1995) Developing motor neurons rescued from programmed and axotomy-induced cell death by GDNF. Nature 3730:344-346.

Oppenheim RW, Prevette D, Grieshammer U, Lewandoski M, Martin GR (1997) The survival of mouse embryo spinal motoneurons and interneurons following genetic deletion of skeletal muscle. Soc Neurosci Abstr 23:1157.

Pachnis V, Mankoo B, Costantini F (1993) Expression of the c-ret protooncogene during mouse embryogenesis. Development 119:1005-1017.

Pennica D, Shaw KJ, Swanson TA, Moore MW, Shelton DL, Zioncheck KA, Rosenthal A, Taga T, Paoni NF, Wood WI (1995) Cardiotrophin-1: biological activities and binding to the leukemia inhibitory factor receptor/gp130 signaling complex. J Biol Chem 270:10915-10922.

Pennica D, Arce V, Swanson TA, Vejsada R, Pollock RA, Armanini M, Dudley K, Phillips HS, Rosenthal A, Kato AC, Henderson CE (1996) Cardiotrophin-1, a cytokine present in embryonic muscle, supports long-term survival of spinal motoneurons. Neuron 17:63-74.

Riethmacher D, Sonnenberg-Riethmacher E, Brinkmann V, Yamaai T, Lewin GR, Birchmeier C (1997) Severe neuropathies in mice with targeted mutations in the ErbB3 receptor. Nature 389:725-730.

Robertson K, Mason I (1997) The GDNF-RET signalling partnership. Trends Genet 13:1-3.

Sanchez MP, Silos-Santiago I, Frisen J, He B, Lira SA, Barbacid M (1996) Renal agenesis and the absence of enteric neurons in mice lacking GDNF. Nature 382:70-73.

Sendtner M, Stockli KA, Thoenen H (1992) Synthesis and localization of ciliary neurotrophic factor in the sciatic nerve of the adult rat after lesion and during regeneration. J Cell Biol 118:139-148.

Sendtner M, Gotz R, Holtmann B, Escary JL, Masu Y, Carroll P, Wolf E, Brem G, Brulet P, Thoenen H (1996) Cryptic physiological trophic support of motoneurons by LIF revealed by double gene targeting of CNTF and LIF. Curr Biol 6:686-694.
Sheng Z, Pennica D, Wood WI, Chien KR (1996) Cardiotrophin-1 displays early expression in the murine heart tube and promotes cardiac myocyte survival. Development 122:419-428.

Snider WD (1994) Functions of the neurotrophins during nervous system development: what the knockouts are teaching us. Cell 77:627-638.

Treanor JJ, Goodman L, de Sauvage F, Stone DM, Poulsen KT, Beck CD, Gray C, Armanini MP, Pollock RA, Hefti F, Phillips HS, Goddard A, Moore MW, Buj-Bello A, Davies AM, Asai N, Takahashi M, Vandlen R, Henderson CE, Rosenthal A (1996) Characterization of a multicomponent receptor for GDNF. Nature 382:80-83.

Trupp M, Arenas E, Fainzilber M, Nilsson AS, Sieber BA, Grigoriou M, Kilkenny C, Salazar-Grueso E, Pachnis V, Arumae U, Sariola H, Saarma M, Ibanez CF (1996) Functional receptor for GDNF encoded by the c-ret proto-oncogene. Nature 381:785-788.

Wong V, Glass DJ, Arriaga R, Yancopoulos GD, Lindsay RM, Conn G (1997) Hepatocyte growth factor promotes motor neuron survival and synergizes with ciliary neurotrophic factor. J Biol Chem 272:5187-5191.

Wright DE, Snider WD (1996) Focal expression of glial cell line-derived neurotrophic factor in developing mouse limb bud. Cell Tissue Res 286:209-217.

Yamamoto Y, Livet J, Pollock RA, Garces A, Arce V, deLapeyrière O, Henderson CE (1997) Hepatocyte growth factor (HGF/SF) is an essential muscle-derived survival factor for a subpopulation of embryonic motoneurons. Development 124:2903-2913.

Yan Q, Johnson EMJ (1988) An immunohistochemical study of the nerve growth factor receptor in developing rats. J Neurosci 8:3481-3498.

Yan Q, Matheson C, Lopez OT (1995) In vivo neurotrophic effects of GDNF on neonatal and adult facial motor neurons. Nature 373:341-344.

Yin QW, Johnson J, Prevette D, Oppenheim RW (1994) Cell death of spinal motoneurons in the chick embryo following deafferentation: rescue effects of tissue extracts, soluble proteins, and neurotrophic agents. J Neurosci 14:7629-7640.

Zurn AD, Winkel L, Menoud A, Djabali K, Aebischer P (1996) Combined effects of GDNF, BDNF, and CNTF on motoneuron differentiation in vitro. J Neurosci Res 44:133-141. 